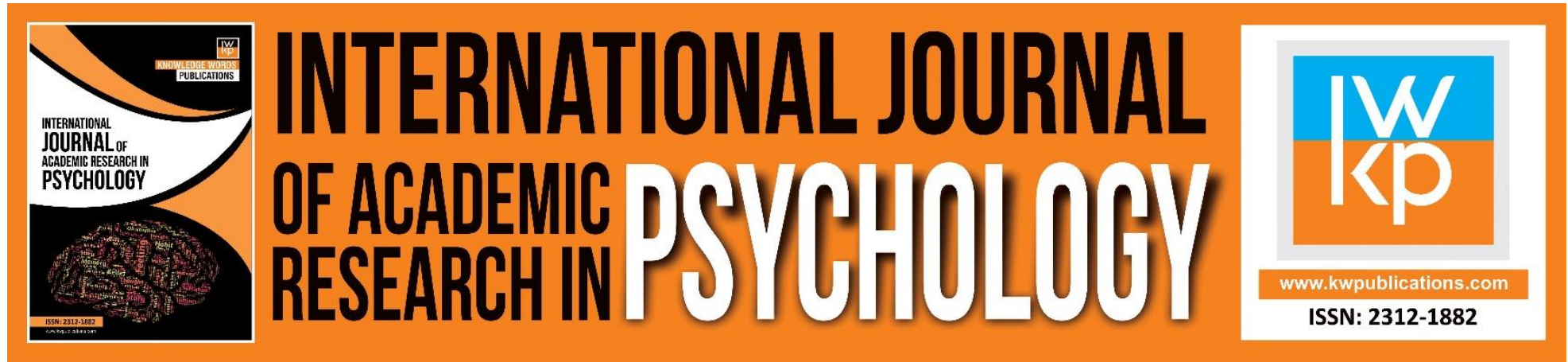

\title{
Crises of Maturity and Sexual, Behavioral and Psychological Problems related to Girls with Intellectual Disability
}

Fariborz Sedigh Arfe-ee, Ali Yazdakhasty, Sara Afshar, Hamid Rahimi, Mohammad Normohammadi Najaf Abadi

To Link this Article: http://dx.doi.org/10.46886/IJARP/v1-i1/1253

DOI:10.46886/IJARP/v1-i1/1253

Received: 06 May 2014, Revised: 17 July 2014, Accepted: 19 August 2014

Published Online: 26 August 2014

In-Text Citation: (Arfe-ee et al., 2014)

To Cite this Article: Arfe-ee, F. S., Yazdakhasty, A., Afshar, S., Rahimi, H., \& Abadi, M. N. N. (2014). Crises of Maturity and Sexual, Behavioral and Psychological Problems related to Girls with Intellectual Disability. International Journal of Academic Research in Psychology, 1(1), 26-34.

Copyright: (c) 2014 The Author(s)

Published by Knowledge Words Publications (www.kwpublications.com)

This article is published under the Creative Commons Attribution (CC BY 4.0) license. Anyone may reproduce, distribute, translate and create derivative works of this article (for both commercial and non-commercial purposes), subject to full attribution to the original publication and authors. The full terms of this license may be seen at: http://creativecommons.org/licences/by/4.0/legalcode

Vol. 1, No. 1, 2014, Pg. 26 - 34

https://kwpublications.com/journals/journaldetail/IJARP

JOURNAL HOMEPAGE

Full Terms \& Conditions of access and use can be found at https://kwpublications.com/pages/detail/publication-ethics 


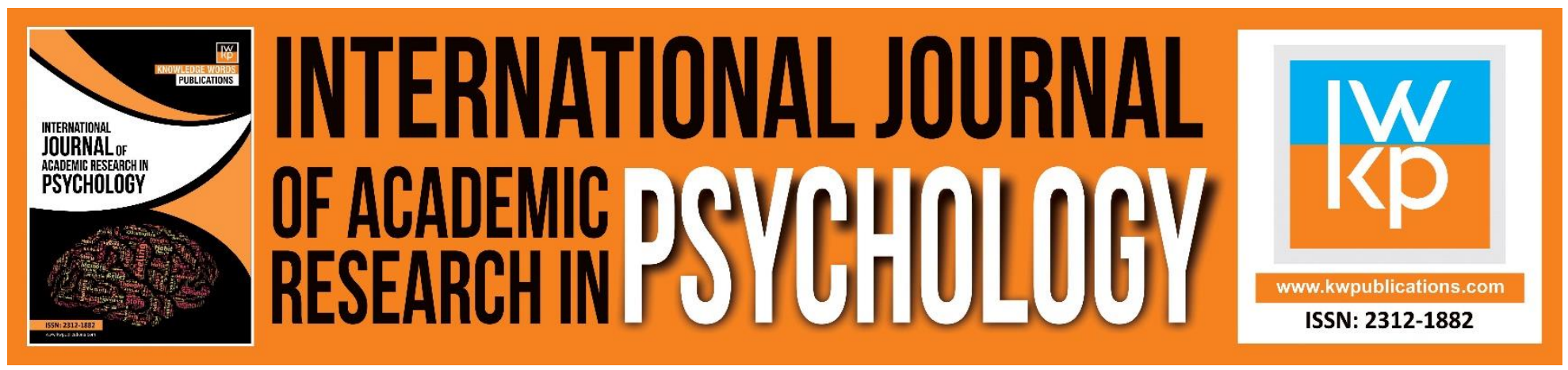

\title{
Crises of Maturity and Sexual, Behavioral and Psychological Problems Related to Girls with Intellectual Disability
}

\author{
Fariborz Sedigh Arfe-ee, Ali Yazdakhasty \\ Associate Professor at Department of Psychology, University of Kashan, Iran \\ Email: fsa@kashanu.ac.ir, Yazdakhasty@yahoo.com \\ Sara Afshar \\ MA student in Psychology, University of Kashan, Iran \\ Email: goolenarges69@gmail.com \\ Hamid Rahimi \\ Assistant Professor at Department of Educational, University of Kashan, Iran \\ Email: dr.hamid.rahimi@kashanu.ac.ir

\section{Mohammad Normohammadi Najaf Abadi \\ MA student in Psychology, University of Kashan, Iran \\ Email: mnornajafabadi@yahoo.com}

\begin{abstract}
People with intellectual disability in addition to having an IQ lower than normal are with the disorder in adaptive behavior. Adolescence is especially important for girls and boys with intellectual disability and is one of the important issues in the period for these people is the maturity issue is known as the crisis and followed by mental, behavioral and sexual problems for them. The aim of this study was to investigate the crisis of puberty and mental health, sexual and behavior problems in girls mentally retarded and providing effective ways to deal with these problems. For this reason, to take advantage of descriptive-documental method and review necessary information scientific literature in the field of adolescence crisis and related problems in girls with intellectual disability have been collected. Most findings indicate an increase in the prevalence of mental and behavioral disorders in mentally retarded adolescents is during puberty. The most important mental and behavioral disorders in adolescence and maturity in people with mental retardation are: mood disorders, depression disorders, Psychotic Disorders, Anxiety Disorders, attention deficit disorders. The research also show
\end{abstract}


that the people cannot acquire knowledge from other people's about the issues of maturity and have not ability to read the books and magazines and in the schools usually there is no the necessary and sufficient time. The results also indicate that in both normal and mentally retarded persons existence some features may be increase the tendency of people to sex crimes in adolescence including: defect of behavioral- cognitive skills and evaluation and processing skills, the being humiliation and ignored by others, lack of confidence, sexual fantasy, and in most cases the patterns that cause sexual arousal. According to the research results, it find that the risk of sexual abuse in people with intellectual disability is more than normal people. Problem of mentally retarded girls and lack of skill in applying cognitive strategies for solving problems, lack of understanding and acquiring of proper intentions of others, has restrictions in viewing behavioral consequences and providing a more limited solutions to solve individual problems in creating sexual- behavioral and mental problems. Mental retarded girls with having the lower IQ and impairment in adaptive behavior to solve individual and social problems has major flaws. So mature and its major changes can to make a major mental and behavioral sexual problems for them and their families. At the end, propose solutions for dealing with such sexual- behavior and mental problems in maturity of the people is necessary, including: increase the control over the people - Increase the skills of teachers in dealing with the problems of the individual, increase opportunities for special schools to deal with abuse and sexual problems such subjects with holding extra-curricular programs.

Keywords: Puberty, Puberty Crisis, Behavioral Problems, Mental Problems, Sexual Problems, Intellectual Disability.

\section{Introduction}

Adolescence is one of a long period of life with rapid growth and changes in cognitive, emotional, social and physical. Puberty is first step of adolescence and may be one of the challenges of this period. Puberty is process of physical change that its main characteristic is growthinstinct and secondary sex characteristics (Mikouchi, 2003). Puberty is origin of many variations on the individual and physical changes of puberty has the strong effect on the psychological, behavioral, social and mental of the people and change emotional and psychological tendencies, which is why the rate of prevalence of behavioral disorders like anxiety, aggression, sexual problems and delinquencyare increased in this period (Ahadi \& Mohseni, 1999).

Mental retardation is such the phenomenon that getting it makes a lot of problems for the patient and his family. These individuals also lower than normal IQ have adaptive behavior disorder. They have major defects in personal and social problems-solving and understanding of the laws governing the community and having skills of self-supporting in different positions. Adolescence is a special and important period for girls and boys mentally retarded. Mentaldisorder decreases a teen's capabilities than most his teenager group with normal IQ in the population and may be provide the incidence of psychiatric, behavioral and characteristic disorders. In addition, the puberty is the maturity period and in this period primary and secondary sex characteristics develop and will have functionality, and these changes in individuals with intellectual disability is considered as an important occurrence, and most families are faced with a crisis and makes a variety of chocolate (Massey, 2000). 
INTERNATIONAL JOURNAL OF ACADEMIC RESEARCH IN PSYCHOLOGY

Vol. 1, No. 1, 2014, E-ISSN: 2312-1882 @ 2014 KWP

\section{Most Important Mental and Behavioral Disorders of Puberty in Girls with Intellectual Disability Include}

A disturbance of mood: Anxiety, phobias, OCD, bitterness and somatic diseases includes common disorders. The first common symptoms are different changes in vital functions including reducing appetite and insomnia. Stressful events are often the cause of this disorder. But life changes are usually able to create these disorders (Amank, 2000). Severe depression, social withdrawal, reversible of actions that relate to the period before living such as: addiction, deterioration of the performance and behavior of children and mental and psychosomatic retardation (Massey, 1998).

Depression: Depression often occurs during puberty in adolescents with intellectual disability and the disorder affects educational and emotional progress of individuals (Massey, 2000).

Psychotic disorders: From the perspective of clinical, various forms of schizophrenia can be seen in mentally retarded. Common symptoms in this disorder include: credulity, delusions and simple hallucinations, thought disorders, especially verbal expressions, word making, frequent prate, excessive or numbness motional activities. The disorder is often associated with behavioral symptoms such as of aggressive andimpulsive behavior and self-harm (Village, 1998).

Anxiety disorders: Anxiety disorders in mentally retarded often occurs in different forms such as: aggression, anger, fear and crying and in some cases of anxiety disorder can equal to generalized anxiety disorder. In the cases that cognitive impairment is less and people can talk about their anxiety, diagnosis is easier. In other cases, the diagnosis is only hypothetical. Among the common anxiety disorders in this period are phobias and obsessions era. The obsessive treatments in adolescents with intellectual disability can make compulsive disorder (Massey, 2000).

Attention Deficit Disorder: Attention deficit disorder/hyperactivity is a problem, which about 5 to 10 percent of all children suffer. These patients suffer from distraction, inattention, impulsivity, and hyperactivity. Generally they have trouble in learning, tracking and finishing the tasks, make friends and keeping friends. Prevalence of attention deficit disorder according to the statistics of the organization of Psychiatry Americain mental retardation in 9 to 18 times higher than the general population, and especially in people with hyperactivity and attention deficit, puberty and adolescence and simultaneous changes may be increasing the risk of this complication (Melentir, 2000).

Sexual problems and issues: sexual motivation sin some of about maturity, in some of people appears from the adolescence steps and even in some of people from stage 5 to 6 years. However, development and peak of the mode is in maturity and adolescence ages (Ghaemi, 1998). Sexual function is effected by environmental factors of biological, psychological and sociological. Internal and external genitals, Hormones and neuro-hormone, social and economic status and the dominant social customs and style all affect expressing sexual desires (Ghobadi, 2002). Problem srelated to the girls and boys with mental retardedgradually increase along with age of them, its other word, status of the people is that faces with more problems in higher ages than the childhood. Sexual problems and demonstration are including cases that create the weighty issues for them and their family 
resortthem to the non-logical solutions to the fix the problems (Chastr, 2000). Level of knowledge about sexual issues in people with intellectual disabilityis lower than the normal people. The people have a vague and partial or wrong and inappropriate information about pregnancy,sexually transmitted diseases, homosexuality and other sexual deviations. one of the reasons of limitations of the knowledge in them is weakness of social and verbal skills in them, these people to inform the issues cannot acquire information required from other people and they have not ability to reading book and magazines in the field as sources of information and comprehension, usually in schools there is no special curriculum for training such issues and moreover education about its sex and differentiation between two sex and necessary and sufficientopportunities (Timas, 2002). Behavior ssuch asshowing genitals, lack of hidingits sexuality in public, expressing tendency to the relationship with others even the familyin terms of contrast with humanethical and social criteria threats family in terms of dignity and prestige and they think to find the fast and sometimes sectional solutions. For example, sometimes family of the people complaining about that theirdaughter express strongly its sexual. Should be known except for the rare cases which young, teen or even child withmentally retardeddue to hormonal problems suffered sexual overstimulation.in other cases, background of sexual demonstration in such people has environmental origin and should be think about the comprehensive solutions including drug treatment and educational seeking choice, maybe if we know what factors cause increase and the incidence of the demonstration achieve to answer of a lot of questions (Davarmanesh, 2001). The including issues cause to create problems for the people withmentally retardedand their family is masturbation, in the people with mentally retarded like normal people there is masturbation but in adolescents and young with mentally retardedthe problems is along with thelarge problems. Because the masturbation usually is seen in public locations and in inappropriate times and more frequently and for long form and sometimes cause injury and damage to the people, sexual crime in people with mentally retarded rarely seen (EstGate, 2006). But some of factors increase risk of sexual crimes in this people, including: sexually abused, the lack of information and sufficient education about sexual issues, disability in learning community terms about sexual behavior. If there are sexual crimes, cognitive - behavior therapy can reduce sexual crimes (Emerson, 2003).

\section{Background of the Study}

Laingh quote of Swartz \& Master express thatin both group of normal people and mentally retarde dones existence of the following feature may increase the people tendency to the sexual crimes, the symptoms and marks are: impairment of behavioral - cognitive skills and processing and evaluation skills, indifference and being humiliated by others that in some cases leads to create depression modes in people, lack of confidence, sexual imagination and in more cases the patterns which causes to sexual excitation and usually the patterns is same in both group of normal people and mentally retardedones (Lane, 1999). Teenagers with mentally retarded show a keen interest in the opposite sex andoften cause to concern parents. Defects in social skills cause the people show inappropriate behaviors in against opposition sex and often provides the ground for sexual abuse of them. It should be mentioned that the risk of sexual abuse of people with mentally retardedis more than the common people. Some statistics show 39 to 68 percentage of girls with mentally retardedbefore age 18 are sexually abused and the action be carried out by different people (Gold Stein, 2001). In regard to sexual problems in people with mentally retarded so far little research has been done, in 2003 a 
research in order to study sexual problems was done by Thomson, in this research 86 teens with mentally retardedbetween ages 12 to 20 were selected and PIMRA - S questionnaire was used to investigate the sexual problems, results show the sexualanomalous behaviors including: showing genitals and intense sexuality than opposite sex in the public locations in people with mentally retardedin the different environments including school, house and work environment are seen (Thompson, 2003). In 2006 a research was conducted by Beravent to study and evaluate sexual problems of normal and with mentally retardedadolescent girls. In this research 100 teens with IQ 50 to 70 and 100 teens with normal IQ in ages12, 16 were selected and interviews were done with parents - teachers. outcomes of the research show there is a difference between two group of the girls the in the field of problems such: sexual demonstration in against opposite sex, sexual panacheand going to public with genital and the problems in girls with mentally retardedwas more than normal girls and some of mothers of girls with mentally retardedconcern about the problems in their girls (Beravent, 2006).

Alspet (2004) quoted fromAnderson (1987) suggests that generally prevalence of psychotic and behavioral disorders in adolescence with mentally retarded, 3 to 4 percent increase after puberty. He placed these disorders in adolescence in a multi-category:

- Destructive and anti-social behaviors (extraversion disorders) that its prevalence is between 3 to 5 percent.

Emotional problems and disorders (introspection disorders) that its prevalence is between 2 to 5 percent.

- A combination of mental and behavioral problems and physical disorders that its prevalence is between 1 to 3 percent. (Alsept, 2004). Liu (2000) conducted a study with aim of behavioral problems in adolescent girls with mentally retardedand normal adolescents in China. In this study, 85 adolescent girls between ages 11 to 18 were selected and were studied. The tools used in the study was Robert Hutton's scale of dimension of social and emotional, the scores obtained on each scale suggested that the prevalence of behavioral problems was in maturity and in scales of avoidance of interactions with friends, engage with aggression, avoidance of interaction with the teacher, inappropriate behavior, reactions indicative of depression and physical awesome reactions, mental retardation achieved higher scores (Liu, 2000). In 2002 "Dikcer" conducted a research to study and assess emotional and behavioral problems in normal adolescents and those who with intellectual disability. The results showed that problems like anxiety, depression and somatic complaints of educable people with retardation was more than trainable people with retardation and the cases such problems of attention, aggression, cogitation, thinking and isolation problems in both groups of mentally retardedmore prevalent than in the general population (Dicker, 2002).

According to the above subjects, the articleintended to examine the crisis of puberty and mental health, sexual and behavioral problems in girls with intellectual disability and provide effective solutions to deal with these problems by descriptive -documental way and search in the existing literature and valid.

\section{Methods}

Methods of the study was a descriptive-documental. And has been tried to collect and review scientific authoritative sources of necessary information regarding the crisis of puberty and the problems related to it in girls with mental retarded. 


\section{Results}

The findings suggest that behavioral problems in children and adolescents with intellectual disability is more than subjects with normal IQ its reasons are those cause to create these problems in normal children and adolescents. Moreover, special problems that seen in individuals with intellectual disability should be considered low intelligence associated with emotional failure, characteristic problems and behavioral disorders (Emerson, 2005). Considering the findings also could be said that people with intellectual disability in different course of life (childhood, adolescence, adulthood) are seen more emotional and behavioral problems in them and this problem can have several causes, for example, states such as anxiety, depression, sadness and seclusion, lack of sympathy of others leads to increased aggression and on the other parent is not involved in social activities and the less support the family and friends is an important factor in isolation of the individual (Bilo, 2003). It should be noted that the correct interaction of parents and youth has important role in creation of appropriate behaviors. The parents who deal with children with intellectual disability by aggressive and punitive behavior use harsh parenting strategies including physical and verbal attacks. They are less able in response to their children's needs and solve the problems and their tolerance to understand their children's wrong behavior is low. It causes to prevalence behavioral problems in children and depressed mothers who are away from their children and because of the anxiety and guilt in response to the needs on their children is unstable and cause negative emotions. In addition some the improper practices are taught through ongoing interpersonal interactions within the family and parents and relatives using improper methods cause to strengthen undesirable behaviors (Duffy, 1998).

\section{Conclusion}

Adolescence is associated with physical and mental rapid changes. During this period, physical growth, followed by mental and emotional changes, and teenagers become curious andsensitive to the changes. Therefore, the psychological and behavioral disorders are increased. Should be noted that important the girls and boys with intellectual disability also enter to adolescence and maturity and have different changes of this period, including prevalence of sexual secondary traits and sexual desires with the difference that the group the due to having low IQ have with more problems. This group of adolescents is excluded due to mental constraints, in use of educational resources that a use of it requires mental ability and on the other hand their limited relationship with community intensifies this process. In adolescents with intellectual disability due to weak of the cognitive, social, verbal skills and limited of their aware about sexual issues, sexual demonstration is more seen and sometimes the environment where the person life provide the ground for this, the people are disable in learning social terms and regulations and for this reason indicates sexual desires in the presence of others. with regard to the results and findings achieved, release of mentally retarded individuals is out of moral solutions, so should be attempted to control their deviant ideas and sectional sexual behaviors by proper and mentally fit them training and the provision of suitable places for games and entertainment of them. In this regard should be use experienced trainers' education and training that meets the needs of these children and as well as have the spirit of patience and compassion for these children. Physical and motional games for the children can drain their emotions. Crafts such as sewing, embroidery, carpentry, painting and many other simple crafts can be effective in the control of these children. 
INTERNATIONAL JOURNAL OF ACADEMIC RESEARCH IN PSYCHOLOGY

Vol. 1, No. 1, 2014, E-ISSN: 2312-1882 @ 2014 KWP

\section{Acknowledgement}

I thank the University of Kashan that helped me in this paper.

\section{Corresponding Author}

Sara Afshar

MA student in Psychology, University of Kashan, Iran

Email: goolenarges69@gmail.com

\section{References}

Ahadi, H., NikChehreh, M. (1999). Developmental psychology (basic concepts in psychology of youth and adolescence). Tehran: Publisher: Pardis [Persian].

Amank, B. (2000). Behavior problem and behavior management strategies in adolescent with mental Retardation, Journal of Intellectual Disability Research. 107-108.

Beravent, M. C., Koot, H. M. (2006). Assessing sexual problems in children with intellectual disability. Autism Development Disorder, 12(6), 223-10.

Buelow, J. M. (2003). Behavior and Mental health problems in children with epilepsy and Low IQ, JM, Dev Med Child Neural , 45, 683-692.

Davarmanesh, A. (2001).Problems of sexual puberty in mental retardation Tehran. USWR; 15: 5-12. [Persian].

Dekker, M. C., Koot, H. M. (2002). Assessing emotional and behavioral problemsin children with intellectual disability, revisiting the factor structure of the developmental behavior checklist, Autism DevDisorder, 32, 601-610.

Duffy, S. A., Jacobson, J. W. (1998). The association between psychiatricdiagnoses and sever behavior problems in mental retardation, Annals of Clinical Psychiatry, Broth wick, 29, 20-24.

Eastgate, G. (2006). Sexual health for people with intellectual disability. SaludPublicaMex, 50 (supply 2), S255- S259.

Elspeth, A. (2004). Comparing rates of psychiatric and behavior disorders in adolescents and young adult with mild intellectual disability with and without Autism, Journal of Autism and Developmental Disorders, 40, 30-37.

Emerson, E. (2003). Prevalence of sexual disorders in children and adolescents with and without intellectual disability. J Intellect Disable Res, 43(9), 70-8.

Emerson, E. (2005). Prevalence of psychiatric disorders in children and adolescents with and without intellectual disability, J. Intellect Disablers, 47, 51-58.

Ghaemi, A. (1998). Family and sexual problems. Tehran: Council of Parents and Educators;20-3 [Persian].

Stein, G. H. (2001), Menarchemenstruation, sexual relations and contraception of adolescent females with Down syndrome. Department of Obstetrics and Gynecology, 18(4), 343-9.

Kighobadi, S., Noghabi, A. (2002). Mental health. Tehran, Boshra. p.11-15. [Persian].

Lmelntyre, L. (2000). Behavior/mental health problems in young adolescence withintellectual disability the impact a families, J. Intellect Disablers, university of California, USA, 5-6.

Laingh, A. (1999). People with mental retardation \& sexual abuse.MPA, health promotion \& disability prevention. Am Acad Child Adolescent psychiatry, 28(7), 552-61. 
Liu, X. (2000). Behavioral and emotional problems in Chinese children with mental retardation and without intellectual disability, J Am Acad Child AdolescentPsychiatry, 30869-903.

Mikouchi, J. (2003). Adolescence and family therapy: translated by Mahshid Yasasei. Tehran: Publishing: Ghoghnous.

Masi, G. (2000). Generalized anxiety and obsessive- compulsive bipolar comorbiditydisorder in adolescents and youngadult with mild mental retardation, J. Intellect Disable, 63, 54-24.

Masi, G. (1998). Psychiatric Illness in mentally retarded adolescents: clinical Features, J. Intelleddisable. 54, 5,300-2

Schuster, M. A., Bell, R. M. (2000). Communication between adolescents and physicians about sexual behavior and riskprevention. Arch Podiatry Adolescent. 20(10), 42-3.

Timma, S. (2002). Adolescent sex offenders with mental retardation literaturereview and assessment considerations, aggression and violent behavior. J Intellect Disable Res, 10(4), 35-9.

Tompson, J., Creary, B. D. (2003). Psychiatric aspects of sexual abuse involving persons with developmental disabilities. Intellect Disable Res. 61(11), 101-6.

Wileg, J. (1998). Expressive Communicative ability symptoms of mental illness and aggressive behavior, Journal of Clinical Psychology, 53, 307-318. 